\title{
Alaomorphus Candèzei
}

novum genus et nova species Elateridarum.

\author{
Beschrieben von
}

\section{Dr. G. Hauser in Erlangen.}

Frons lata, antice sulcis duabus haud profundis, versus labrum divergentibus; labrum magnum. Antennae breves, in ơ longe flabellatae, in + pectinatae, articulis primo excepto in $\sigma^{\top}$ brevissimis, in 우 latitudine longitudine dupla. Prothorax superficie antice valde convexa, lateribus rotundatis, marginatis, angulis posticis divaricatis, subtus sulco ad antennas recipiendas brevi, prosternum versus labium dilatatum. Coxarum posteriorum laminae extrorsum dilatatae, margine posteriore subconcavo. Pars elytrorum anterior leviter dilatata et margine deflexo. Pedes a latere compressi, tarsis et unguiculis simplicibus.

Stirn mit 2 seichten, ziemlich breiten, nach vorn divergirenden Furchen, Vorderrand leicht stumpfwinklig ausgeschnitten, die Ecken über den Fühlern schräg abgestutzt und ebenfalls leicht eingebuchtet; Oberlippe grofs, vorn abgerundet, mit etwas gewulstetem Rand. Fühler des $\sigma^{\top}$ fächerförmig, ohne die Fortsätze sehr kurz, nicht die Mitte des Halssch. erreichend, die des lang gekämmt, kaum $\frac{2}{3}$ so lang wie das Halssch. Erstes Fühlerglied ziemlich grofs, beim $\sigma^{\top} \mathrm{mehr}$ als halb so lang, wie die folgenden Glieder zusammen, kegelförmig, leicht gekrümmt, von hinten her abgeflacht; die folgenden Glieder beim $\sigma^{\uparrow}$ äufserst kurz, kürzer als breit, das 2. Glied unten mit einem kleinen Zahn, das 3. in eine schuppenförmige Spitze auslaufend; das 4.-10. Glied beim $\sigma^{\top}$ mit nach unten und hinten gerichteten, bis zu $7 \mathrm{~mm}$ langen und $1 \mathrm{~mm}$ breiten blätterförmigen Fortsätzen, deren stumpfe, mit einem sehr kleinen Börstchen besetzte Spitze erheblich nach rückwärts gekrümmt ist; den längsten Fortsatz trägt das 4. Glied, die Fortsätze der vor und hinter diesem gelegenen Glieder allmählich etwas kürzer werdend. Das Endglied beim $\sigma^{\uparrow}$ von dem blätterförmigen Fortsatz nicht deutlich abgesetzt, vielmehr diesen unmittelbar bildend, mit stumpfer Spitze und einer etwa bis zur Hälfte des Fortsatzes reichenden undeutlichen kantenförmigen Erhebung an der Oberfäche. 
Beim $ᄋ$ sind die Fühlerglieder vom 4. Gliede ab beträchtlich länger als beim $\widehat{\jmath}$, vom 5 . an etwa doppelt so lang als breit, die nur leicht geschweiften Fortsätze sind bedeutend kürzer und schmäler, nur bis zu $1 \frac{3}{4} \mathrm{~mm}$ lang und kaum $\frac{1}{2} \mathrm{~mm}$ breit; auch am Endglied ist dieses selbst von dem Fortsatz deutlich abgegrenzt und endigt letzteres mit 3 sehr kurzen und stumpfen, mit je einem kurzen Börstchen besetzten Zäckchen. Augen etwas grofs. Halssch. wie bei Alaus geformt, bei beiden Geschlechtern vorn stark kissenartig gewölbt, fast so lang als breit, die Seitenränder stark abgerundet, ziemlich scharf, durch eine schmale Leiste begrenzt, Vorderrand gerade, die Hinterecken zu ziemlich kurzen, kräftigen Spitzen ausgezogen; der hinterste, flachere Theil des Halssch. mit einer bis an den Hinterrand reichenden breiten leistenförmigen Erhebung und beiderseits von dieser eine grubenförmige, nach dem Hinterrand offene Vertiefung. Das Mittelstück der Vorderbrust wie bei Alaus gegen den Mund concav verbreitert und von den Seitenplatten durch eine erhabene Leiste getrennt, welche nach vorn in eine kurze, aber breit klaffende Fühlerrinne übergeht. Der Fortsatz gegen die Mittelbrust kräftig, nicht sehr lang. Schildchen eiförmig mit 2 seitlichen, kleinen Höckern. Fld. stark gewölbt, nicht ganz $1 \frac{3}{4}$ mal so lang als breit, am Grunde kaum breiter als das Halsschild, sich fast bis zu den Platten der Hinterhüften leicht gerundet erweiternd, der Seitenrand dieses erweiterten Theiles aber steil nach abwärts umgebogen; von den Platten der Hinterhüften an die Fld. fast plötzlich eingeengt und dann nach hinten sich allmäblich noch weiter verjüngend, das Ende jeder Fld. stumpf abgerundet; nach vorn die Fld. ziemlich steil abfallend und ihr Vorderrand mit dem hinteren Abschnitt des Halssch. eine tiefe sattelförmige Einsenkung bildend; Schulterecken stumpf. Platten der Hinterhüften sich nach aufsen leicht verbreiternd, ihr Hinterrand etwas concav ausgeschnitten. Beine und Tarsen leicht seitlich zusammengedrückt, letztere und Klauen einfach.

Die Art gleicht in ihrem Ansehen aufserordentlich einem Alaus, steht aber nach dem Bau der Fühler und dem Verhalten der Platten der Hinterhüften näher der Tetralobus-Gruppe. 


\section{Alaomorphus Candèzei.}

Nigro-piceus, nitidus, in omnibus partibus dense squamosus. Caput testaceum, albo-maculatum; prothorax albus parte discoidali posteriori piceo-signata; elytra alba, antice et postice picea, in parte media maculis incanis irregularibus. Subtus prothorax squamis, meso- et metathorax pilis subsquamiformibus albis et testaceis variegati; abdomen albo-squamosum, lateribus testaceo-maculatis, segmento ultimo testaceo. Pedes albo- et testaceo-maculati, tarsis albis. - Long. 26-30 mill., lat. 10-11 mill.

Die beiden Geschlechter sind in Farbe und Zeichnung völlig gleich. Glänzend pechschwarz, Halsschild zerstreut tief punktirt, Flügel an dem abschüssigen Theil der Basis, namentlich nach aufsen kräftig gerippt, die zwischen den Rippen gelegenen tiefen Furchen jenseits des abschüssigen Theiles in 7-8 Punktreihen übergehend, welche sich gegen das 2. Drittel der Fld. allmählich verlieren und an den abgeriebenen Fld. deutlich zu erkennen sind. Der ganze Käfer an Ober- und Unterseite, ebenso an den Beinen mit einem dichten Schuppenkleide besetzt. Dieses an Stirn und Oberlippe goldbraun mit weifsen Punkten und Fleckchen, welche aın oberen Theil der Stirn eine unregelmäfsige Querreihe bilden. Halsschild vorn und an den Seiten weils, in der Mitte der hinteren Hälfte ein grofses, annähernd rechteckiges, quergestelltes und bis zum Hinterrand reichendes dunkelbraunes Feld, in welchem nur vereinzelte kleine weifse Fleckchen sich befinden. Vor den Vorderecken dieses Feldes ist noch je ein kleinerer, unregelmäfsig viereckiger Flecken, welche durch ihre innere untere Ecke mit dem grofsen Feld in Verbindung stehen; der Raum zwischen ihnen unregelmälsig weifs und braun gefleckt; die ausgezogenen Hinterecken des Halssch. heller braun. Schildchen, der abschüssige Theil der Flügelbasis bis etwas über die Höhe herauf, ebenso das letzte Viertel der Fld. dunkelbraun mit eingestreuten heller braunen Schuppen; der dazwischen gelegene Theil der Fld. gröfstentheils weifs, nur im hinteren Abschnitt besonders nach innen unregelmäfsig mäusegrau gefleckt und beiderseits am äufseren Rande, gerade in der Mitte des weifsen Feldes, je ein halbrunder, glänzend schwarzer, nur mit spärlichen braunen Schuppen besetzter Flecken. Der vordere braune Abschnitt der Fld. gegen das weifse Mittelfeld unregelmäfsig zackig begrenzt, ebenso am hinteren braunen $\mathbf{A b}$ schnitt die Grenze unregelmäfsig und hier einzelne kleine braune 
Fleckchen in das weifse Mittelfeld hereinreichend, sowie umgekehrt kleine, weifse Fleckchen in den braunen Abschnitt eingestreut. Vorder-, Mittel- und Hinterbrust mit längeren Haarschuppen dicht besetzt. Mittelstück der Vorderbrust hellbraun mit eingestreuten weifsen Schuppenhaaren, die Seitenplatten hellbraun und weifs gefleckt. Mittelbrust, Hinterbrust und Platten der Hinterhüften grölstentheils hellbraun, nur die Mittelbrust in der Mitte mit sehr zahlreichen weifsen Schuppenhaaren. Die Beschuppung des Bauches wie an der Oberseite; sämmtliche Bauchringe mit Ausnahme des letzten grölstentheils rein weifs, nur ein meistens dreieckiger Fleck vorn am Aufsenrande hellbraun; in der Mitte der Ringe nur vereinzelte hellbraune Schuppen. Hinterrand des vorletzten und der letzte Ring hellbraun, letzterer mit 2 kleinen weifsen Fleckchen. Fühler braun, die Fortsätze graubraun; die Fühlerglieder mit hellbraunen Schüppchen besetzt, die Fortsätze beim $\sigma^{\uparrow}$ mit äufserst kleinen, kaum sichtbaren graubraunen Schüppchen. Beine hellbraun und weifs gefleckt, ebenso die Tarsen, letztere fast ganz weifs.

Bei Ikutha in Englisch Ost-Afrika von meinem Freunde Hrn. Missionar Säuberlich gesammelt und von dem verstorbenen Dr. Candèze als novum genus et nova species Elateridarum erkannt.

\section{Protaetia regalis var. nov. Horni Kraatz.}

Corpore valido, gibbo, atro, supra opaca, thorace 6-punctato, elytris 8-guttatis, subtus nitida, pallide guttata. - Long. 23 mill.

Patria: Ceylon (Matabele).

Diese, durch tief schwarze Färbung ausgezeichnete Var. der schönen, gedrungenen, $\mathrm{k} u \mathrm{p}$ ferrothen regalis aus Vorderindien scheint in Ceylon nur sehr selten vorzukommen, denn Dr. Horn brachte nur $2 \mathrm{Ex}$. derselben mit (von denen er mir das eine freundlichst überliefs) und Neevoort van de Poll erwähnt in seiner Aufzählung der von J. Z. Kannegieter in Ceylon gesammelten Cetoniden (Leyden Notes XIII [1891] p. 87) auch nur 2 Ex.

Zum schweren Erkennen meines Ex. der var. Horni trägt der Umstand bei, dafs die 4 Flecke in der Mitte des Halsschildes viel deutlicher hervortreten als bei meiner regalis. Der von Burmeister erwähnte Fleck am Vorderrande fehlt sowohl bei meiner Horni als bei meiner regalis.

Dr. G. Kraatz. 


\section{$2 \mathrm{BHL}$ Biodiversity Heritage Library}

Hauser, G . 1900. "Alaomorphus Candèzei novum genus et nova species Elateridarum." Deutsche entomologische Zeitschrift 1900(1), 141-144. https://doi.org/10.1002/mmnd.48019000120.

View This Item Online: https://www.biodiversitylibrary.org/item/103695

DOI: https://doi.org/10.1002/mmnd.48019000120

Permalink: https://www.biodiversitylibrary.org/partpdf/235795

\section{Holding Institution}

Harvard University, Museum of Comparative Zoology, Ernst Mayr Library

\section{Sponsored by}

Harvard University, Museum of Comparative Zoology, Ernst Mayr Library

\section{Copyright \& Reuse}

Copyright Status: Public domain. The BHL considers that this work is no longer under copyright protection.

This document was created from content at the Biodiversity Heritage Library, the world's largest open access digital library for biodiversity literature and archives. Visit BHL at https://www.biodiversitylibrary.org. 